\title{
Isomeric periodic mesoporous organosilicas with controllable properties $\dagger$
}

\author{
Carl Vercaemst, ${ }^{* a}$ Matthias Ide, ${ }^{a}$ Heiner Friedrich, ${ }^{b}$ Krijn P. de Jong, ${ }^{b}$ Francis Verpoort ${ }^{a}$ and \\ Pascal Van Der Voort $* a$
}

\author{
Received 13th July 2009, Accepted 18th September 2009 \\ First published as an Advance Article on the web 15th October 2009 \\ DOI: $10.1039 / b 913961 \mathrm{c}$
}

\begin{abstract}
The synthesis procedure for isomeric periodic mesoporous organosilicas with $E$-configured ethenylene bridges was investigated using the homemade pure $E$-isomer of 1,2-bis(triethoxysilyl)ethene. The $\mathrm{pH}$, aging temperature and the presence of cosolvents played a key role in obtaining well-ordered mesoporous materials with controllable properties and morphologies. By fine-tuning the reaction mixture acidity, PMOs with high surface areas and pore volumes could be attained. By selecting various alcohols as cosolvents and optimizing the alcohol concentration, PMOs with crystal-like disc shaped, fibrous and spherical particle morphologies were obtained. The synthesis temperature of these ethenylene-bridged PMOs influences the pore size, structure, connectivity and volume.
\end{abstract}

\section{Introduction}

The incorporation of organic functionalities into inorganic frameworks via post-synthetic functionalization of inorganic solids or via the co-condensation method has led to organicinorganic hybrid materials with well-defined pore-structures and unique properties. ${ }^{1-3}$ By fusing the properties of organic and inorganic building units within the same network, extremely versatile, robust and hydrothermally stable composite materials are obtained. A relatively novel class of organic-inorganic hybrid materials are periodic mesoporous organosilicas (PMOs). ${ }^{4,5}$ These materials can be synthesized via the direct condensation of bridged organosilanes $\left(\mathrm{R}^{\prime} \mathrm{O}\right)_{3} \mathrm{Si}-\mathrm{R}-\mathrm{Si}\left(\mathrm{OR}^{\prime}\right)_{3}$ in the presence of a structure-directing agent (SDA), either hydrothermally ${ }^{6}$ or through evaporation-induced self-assembly (EISA). ${ }^{7}$ PMOs differ from early organic-functionalized mesoporous silicas (synthesized via the grafting or co-condensation method) in the content of organic groups and in the manner in which these constitute the mesoporous framework. That is, PMOs have a very high amount of organic groups, which are homogeneously distributed throughout the hybrid scaffold, while preserving its structural properties. To date, PMOs with various organic groups, of which the most common are methylene, ${ }^{8,9}$ ethylene, ${ }^{5,10-12}$ ethenylene $e^{4,6,13-16}$ and phenylene, ${ }^{17-19}$ have been developed. Due to their easily tunable physical and chemical properties, PMOs have found their way into different fields, ranging from catalysis ${ }^{20-24}$ and environmental technology ${ }^{25}$ to microelectronics ${ }^{26}$ sensing, ${ }^{27}$ and chromatography. ${ }^{28}$

Here we present the synthesis of diastereoisomeric pure $E$-configured ethenylene-bridged PMOs (E-EBP) with various

${ }^{a}$ Department of Inorganic and Physical Chemistry, Centre for Ordered Materials, Organometallics and Catalysis, University of Ghent, Krijgslaan 281, building S3, 9000 Ghent, Belgium. E-mail: carl. vercaemst@ugent.be; Fax: +32 9264 4983; Tel: +32 92644442

${ }^{b}$ Department of Inorganic Chemistry and Catalysis, Debye Institute for Nanomaterials Science, Utrecht University, Sorbonnelaan 16, NL-3508 $T B$ Utrecht, The Netherlands

$\dagger$ Electronic Supplementary Information (ESI) available: High resolution TEM image of $E$-EBP-15, isotherms of $E$-EBP-11, $E$-EBP-19, $E$-EBP-23, and $E$-EBP-27. See DOI: $10.1039 /$ b913961c/ morphologies, using the triblock copolymer P123 as a structure directing agent. In particular, the influence of several cosolvents and the $\mathrm{pH}$ on the morphology and the overall quality of the resulting ethene-PMOs are studied. Furthermore, the influence of the aging temperature on the pore size and micropore volume is discussed.

\section{Experimental}

\section{Materials}

Vinyltriethoxysilane, Grubbs' 1st generation catalyst, Pluronic $\mathrm{P} 123\left(\mathrm{EO}_{20} \mathrm{PO}_{70} \mathrm{EO}_{20}\right)$ and TEOS were obtained from Aldrich.

\section{Preparation of the diastereoisomeric pure $E$-isomer of 1,2-bis- (triethoxysilyl)ethene}

For the synthesis of the diastereoisomeric pure $E$-isomer of 1,2bis(triethoxysilyl)ethene ( $E$-BTSE), the Grubbs' first-generation catalyst was used, according to a procedure recently reported by our group. ${ }^{6}$ In a typical synthesis of $E$-BTSE, $\left(\mathrm{PCy}_{3}\right)_{2} \mathrm{Cl}_{2}$. $\mathrm{Ru}=\mathrm{CHPh}(0.0535 \mathrm{~g}, 0.065 \mathrm{mmol})$ and vinyltriethoxysilane $(42.95 \mathrm{ml}, 0.2038 \mathrm{~mol})$ were added to a Schlenk flask under argon. The mixture was left to stir for one hour and subsequently refluxed for an additional three hours. Unreacted vinyltriethoxysilane was distilled off, after which E-BTSE was vacuum distilled to give a clear colourless liquid. The overall yield was $33.8 \mathrm{~g}(94 \%)$. The presence of $E$-BTSE was identified by ${ }^{1} \mathrm{H}$ and ${ }^{13} \mathrm{C}$ NMR and GC-analysis as a diastereoisomeric pure product $(\sim 100 \% E) .{ }^{1} \mathrm{H}$ NMR $\left(\mathrm{CDCl}_{3}\right): \delta=6.66(\mathrm{~s}, 2 \mathrm{H})$, $\delta=3.84(\mathrm{q}, 12 \mathrm{H}), \delta=1.23 \mathrm{ppm}(\mathrm{t}, 18 \mathrm{H}) ;{ }^{13} \mathrm{C} \mathrm{NMR}\left(\mathrm{CDCl}_{3}\right)$ : $\delta=145.92,58.82,18.45 \mathrm{ppm}$.

\section{Preparation of ethenylene-bridged periodic mesoporous organosilicas}

In a typical synthesis procedure, $1.00 \mathrm{~g}$ of Pluronic P123 was diluted in an acidified solution containing $47.80 \mathrm{ml}$ of $\mathrm{H}_{2} \mathrm{O}$, $3.42 \mathrm{ml}$ of concentrated $\mathrm{HCl}$ and $2.45 \mathrm{ml}$ of $n$-butanol. The solution was stirred at room temperature for $1.5 \mathrm{~h}$ upon which 
Table 1 Synthesis conditions of the $E$-configured ethenylene-bridged PMOs (E-EBP)

\begin{tabular}{llll}
\hline Sample & Cosolvent & Cosolvent/mmol & $\mathrm{pH}$ \\
\hline$E$-EBP-1 & - & 0 & 1.51 \\
$E$-EBP-2 & - & 0 & 1.21 \\
$E$-EBP-3 & - & 0 & 1.00 \\
$E$-EBP-4 & - & 0 & 0.90 \\
$E$-EBP-5 & - & 0 & 0.85 \\
$E$-EBP-6 & - & 0 & 0.80 \\
$E$-EBP-7 & - & 0 & 0.60 \\
$E$-EBP-8 & - & 26.7 & 0.30 \\
$E$-EBP-9 & $n$-butanol & 26.7 & 1.00 \\
$E$-EBP-10 & $n$-butanol & 26.7 & 0.52 \\
$E$-EBP-11 & $n$-butanol & 26.7 & 0.30 \\
$E$-EBP-12 & $n$-butanol & 26.7 & 0.10 \\
$E$-EBP-13 & $n$-butanol & 26.7 & 0.05 \\
$E$-EBP-14 & $n$-butanol & 16.4 & 0 \\
$E$-EBP-15 & $n$-butanol & 19.8 & 0.30 \\
$E$-EBP-16 & $n$-butanol & 23.3 & 0.30 \\
$E$-EBP-17 & $n$-butanol & 30.2 & 0.30 \\
$E$-EBP-18 & $n$-butanol & 33.6 & 0.30 \\
$E$-EBP-19 & $n$-butanol & 16.4 & 0.30 \\
$E$-EBP-20 & $n$-ethanol & 16.4 & 0.30 \\
$E$-EBP-21 & $n$-propanol & 16.4 & 0.30 \\
$E$-EBP-22 & $n$-pentanol &
\end{tabular}

$1.86 \mathrm{ml}$ of the homemade $E$-BTSE was added. The final reactant molar composition was: P123: $E$-BTSE: $\mathrm{HCl}: \mathrm{H}_{2} \mathrm{O}: n$-butanol = 1: 29: 238: 16097: 155 . This solution was stirred for $4 \mathrm{~h}$ at $35^{\circ} \mathrm{C}$ and successively aged for an additional $16 \mathrm{~h}$ at $90^{\circ} \mathrm{C}$ under static conditions. The mixture was left to cool down to room temperature after which the precipitated PMO was filtrated and washed with distilled water. The surfactant was removed by means of Soxhlet extraction using acetone over a period of $5 \mathrm{~h}$. To investigate the influence of cosolvent, reactant molar ratio, acidity and temperature, a series of different cosolvents (n-ethanol, $n$-propanol, $n$-butanol and $n$-pentanol), different concentrations of $\mathrm{HCl}(0.031,0.062,0.10,0.125,0.141,0.158$, $0.25,0.30,0.50,0.80,0.90$ and $1.0 \mathrm{M})$, or different molar ratios of $n$-butanol:P123 $(95,115,135,155,175,195)$, were used in the synthesis process described above, at various aging temperatures $\left(50,70,90,110\right.$ and $\left.150{ }^{\circ} \mathrm{C}\right)$. Only one reaction parameter was changed in each experiment while keeping the other parameters constant. Details of the PMOs described above are given in Table 1 .

\section{Characterization}

X-Ray powder diffraction (XRD) patterns were collected on a Siemens $\mathrm{D} 5000$ diffractometer with $\mathrm{Cu} \mathrm{K} \alpha$ radiation of $0.15418 \mathrm{~nm}$ wavelength. Nitrogen adsorption experiments were performed at $77 \mathrm{~K}$ using a Belsorp-mini II gas analyzer. Samples were vacuum dried overnight at $90{ }^{\circ} \mathrm{C}$ prior to analysis. The specific surface area, $\mathrm{S}_{\mathrm{BET}}$, was determined from the linear part of the BET plot $\left(\mathrm{P} / \mathrm{P}_{0}=0.05-0.15\right)$. The total pore volume, $\mathrm{V}_{\mathrm{t}}$, was determined from the amount of nitrogen adsorbed at $\mathrm{P} / \mathrm{P}_{0}=0.98$, while the micropore volume, $\mathrm{V}_{\text {mic }}$, was calculated by the $t$-plot method $\left(\mathrm{P} / \mathrm{P}_{0}=0.31-0.51\right)$. The pore size distribution (PSD) was calculated from the adsorption isotherm using the BJH method. The pore wall thickness, $t_{w}$, was estimated using the equation $t_{w}=\left(a_{0}-D_{p}\right)$, where $a_{0}$ and $D_{p}$ are the unit cell dimension and pore size, respectively. Scanning electron microscopy (SEM) images were collected on a Quanta 200 FEG instrument from FEI. Transmission electron microscopy (TEM) samples were prepared by dispersing the PMO material in ethanol using ultrasonication and applying a drop of the solution to a Quantifoil R2/1 carbon support film followed by drying. TEM, including electron tomography (ET), was performed in bright-field mode using a Tecnai T20 (FEI company) electron microscope with a TWIN objective lens and a $\mathrm{LaB}_{6}$ electron source. TEM images were acquired on a $2 \mathrm{k} \times 2 \mathrm{k}$ Tietz CCD camera (TVIPS, Gauting) and ET image series over an angular range of $\pm 70^{\circ}$ at $2^{\circ}$ increments. Recording of ET tilt series was carried out in Xplore3D (FEI company) while alignment and reconstruction of the datasets were performed in IMOD. ${ }^{29}$ For a more detailed description of ET we refer to a recent review. ${ }^{15}$ The ${ }^{1} \mathrm{H}$ and ${ }^{13} \mathrm{C}$ liquid NMR spectra of 1,2-bis(triethoxysilyl)ethene were collected on a Varian Unity-300 spectrometer. GC analysis of 1,2-bis(triethoxysilyl)ethene was conducted on a Finnigan Trace GC ultra GC equipped with a standard FID detector. A wall coated open tubular column with a length of $10 \mathrm{~m}$, an internal diameter of $0.10 \mathrm{~mm}$ and a coating of $0.40 \mu \mathrm{m}$ (5\% diphenyl and 95\% dimethyl polysiloxane) was used. Helium was used as carrier gas at a flow rate of $0.5 \mathrm{ml} \mathrm{min} \mathrm{m}^{-1}$. The inlet temperature was $250{ }^{\circ} \mathrm{C}$ and the split flow was $150 \mathrm{ml} \mathrm{min}^{-1}$. The temperature was kept at $40{ }^{\circ} \mathrm{C}$ for one minute after which it was raised at $200^{\circ} \mathrm{C} \mathrm{min}^{-1}$ to $250{ }^{\circ} \mathrm{C}$ and kept at this temperature for one minute.

\section{Results and discussion}

\section{Optimizing the synthesis of ethenylene-bridged PMOs}

To obtain highly ordered ethenylene-bridged PMOs with high surface areas it is important that the rates of hydrolysis and condensation of the precursor are correctly adjusted to the rate of the template self-assembly. Below the isoelectric point of silica $(\mathrm{pH}<2)$, the silicate species are cationic $\left(\mathrm{I}^{+}\right)$and both the

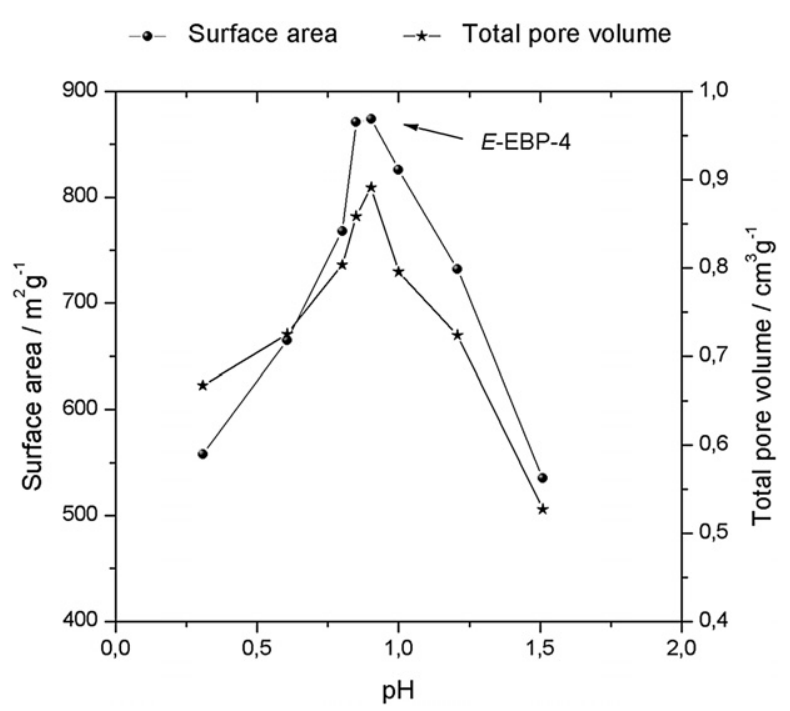

Fig. 1 Surface area and total pore volume as a function of $\mathrm{pH}$ for ethenylene-bridged PMOs synthesized without cosolvent ( $E$-EBP-1 to E-EBP-8). 


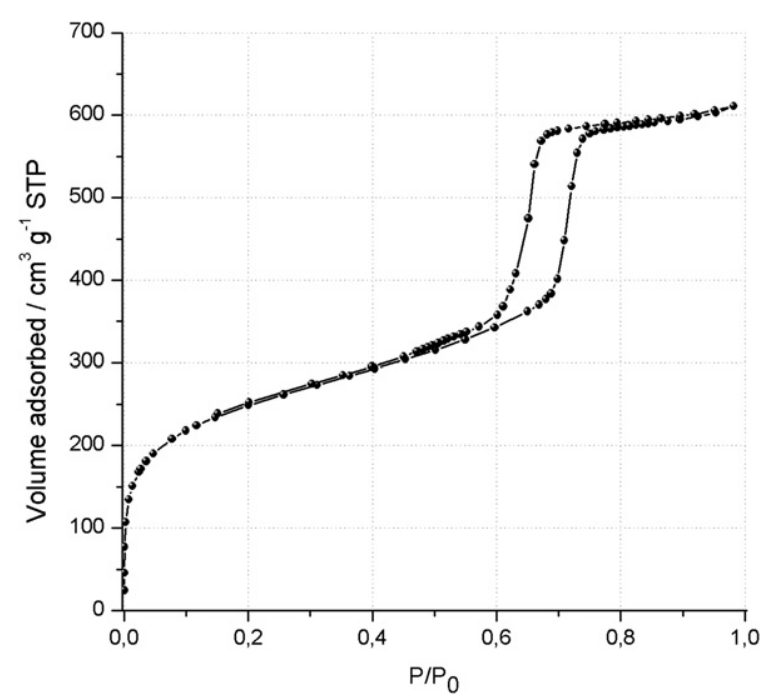

Fig. 2 Nitrogen physisorption isotherms of the ethenylene-bridged PMO synthesized at the optimum $\mathrm{pH}$ value in the absence of a cosolvent (E-EBP-4).

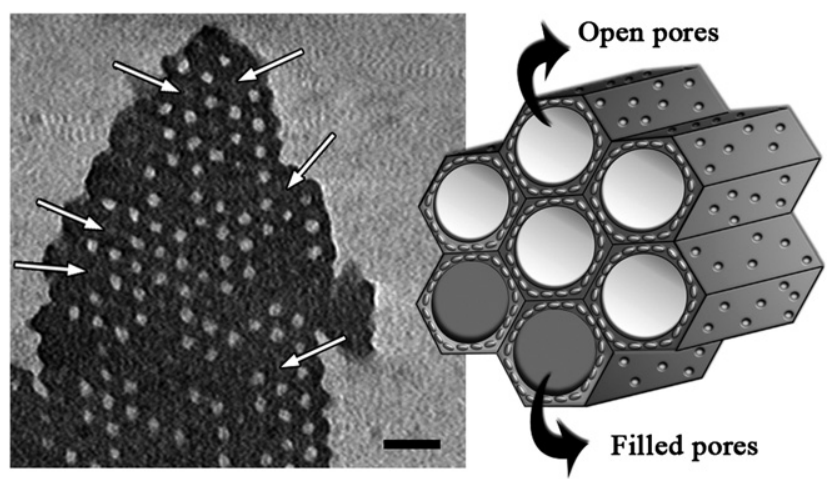

Fig. 3 Numerical cross-section through reconstruction of E-EBP-6, perpendicular to the pore direction. The arrows in the ET image indicate some pores which are filled with solid material. Scale bar is $20 \mathrm{~nm}$.

template-precursor interfacial energy and the condensation rate of the precursor are proportional to the acid concentration. Fig. 1 illustrates the strong influence of the reaction mixture $\mathrm{pH}$ on the surface area and the total pore volume of ethenylenebridged PMOs, synthesized in the absence of a cosolvent.

Both curves reveal an optimum in surface area and pore volume at a $\mathrm{pH}$ of 0.9 (sample $E$-EBP-4). The isotherms of sample $E$-EBP-4, shown in Fig. 2, contain sharp capillary evaporation and condensation steps. When the $\mathrm{HCl}$ concentration is raised beyond this optimum, both the surface area and the pore volume drop significantly. This is most likely caused by the excessive polycondensation rate of the PMO-precursor, relative to the surfactant self-organization, whereby the formation of disordered amorphous material is stimulated. This is corroborated by our previous report in which the influence of the reaction mixture acidity on the blocking of the mesopores is described. ${ }^{15}$ When the synthesis mixture has a $\mathrm{pH}<1$, the excessive polycondensation of the precursor causes filling of the pore channels with solid material, as evidenced by electron tomography (ET). ${ }^{15}$ In Fig. 3 the numerical cross-section of an ethenylene-bridged PMO synthesized at a $\mathrm{pH}$ of 0.8 is presented. While overall a $2 \mathrm{D}$ hexagonal ordering of the mesopores is observed, some are filled with material, that is, no pores are visible in some locations of the 2D hexagonal lattice.

Due to filling of the mesopores with solid material, the nitrogen physisorption isotherms show a characteristic two-step desorption, as seen in Fig. 4. Herein, the desorption step at high relative pressure corresponds to the equilibrium desorption in open mesopores, while the desorption step at low relative pressure is related to cavitation of condensed nitrogen in the blocked mesopores.

On the other hand, when the $\mathrm{HCl}$ concentration is lowered below the optimum, the surface area and pore volume diminish

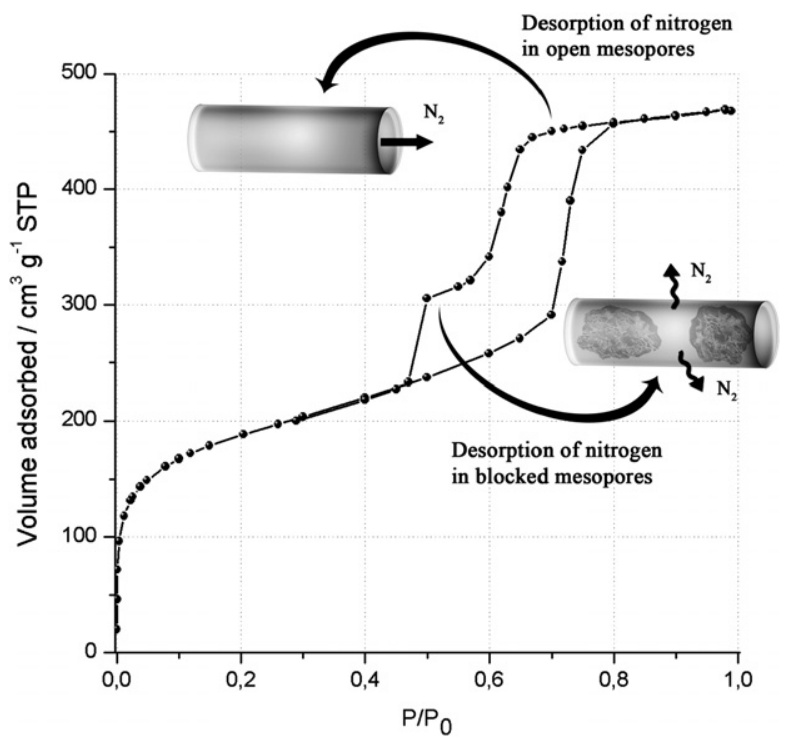

Fig. 4 Typical nitrogen isotherms of an ethenylene-bridged PMO synthesized in the absence of cosolvent at a $\mathrm{pH}<1$ (E-EBP-7). The twostep desorption isotherm is related to the presence of both open cylindrical and blocked mesopores.

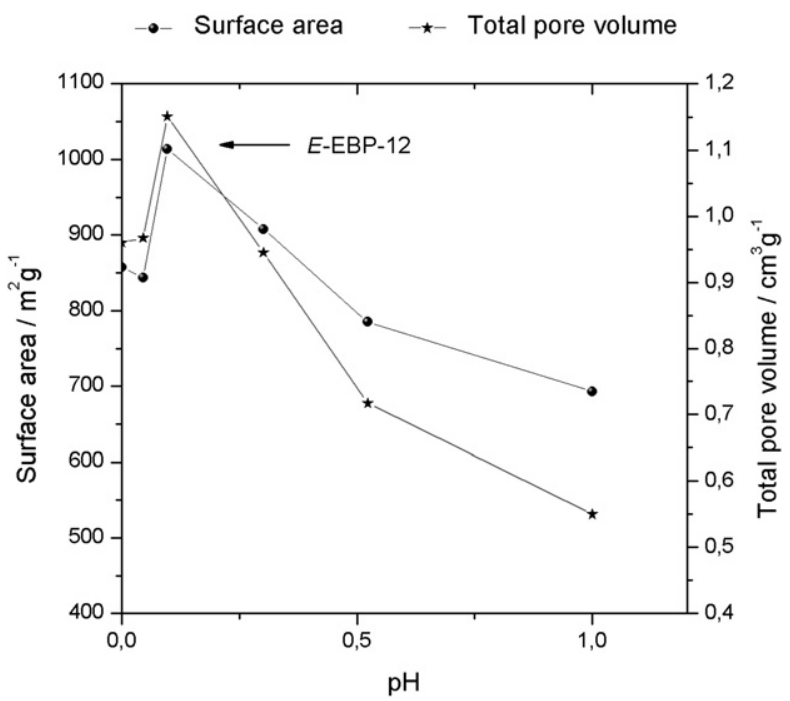

Fig. 5 Surface area and total pore volume as a function of $\mathrm{pH}$ for ethenylene-bridged PMOs synthesized with $n$-butanol (E-EBP-9 to E-EBP-14). 
probably due to the reduced double-layer hydrogen-bonding interaction $\left(\mathrm{S}^{0} \mathrm{H}^{+} \mathrm{X}^{-} \mathrm{I}^{+}\right)$between the nonionic surfactant template $\left(\mathrm{S}^{0}\right)$ and the PMO-precursor $\left(\mathrm{I}^{+}\right)$, whereby the long-range hexagonal packing decreases.

The influence of the reaction mixture $\mathrm{pH}$ on the surface area and the total pore volume of ethenylene-bridged PMOs, synthesized in the presence of $n$-butanol as a cosolvent was also investigated. The results, given in Fig. 5, disclose an optimum in surface area and pore volume at a $\mathrm{pH}$ of 0.10 . In comparison to the synthesis without $n$-butanol (Fig. 1), the optimum is shifted to a significantly lower $\mathrm{pH}$, suggesting that $n$-butanol slows down the polymerization of the precursor.

Under these increased acidic conditions the templateprecursor interaction is more profound, leading to an enhanced aggregation of the nanobuilding blocks into a long-range 2D hexagonally packed architecture. When the $\mathrm{pH}$ is further reduced beyond the optimum, both the surface area and pore volume decrease. However, when compared to the synthesis without $n$-butanol, the decrease is far less intense. This can be explained by the fact that $n$-butanol prevents the filling of mesopores with solid material, even at low $\mathrm{pH}$ values. ${ }^{15}$ Due to the absence of blocked mesopores, typical type IV nitrogen isotherms are obtained as illustrated in Fig. 6.

Taking TEM and XRD results (vide infra) into account, $n$-butanol ensures the formation of 2D hexagonal ordering, which explains the moderate decrease in porosity. The decrease can however be linked to the reduction in micropores, indicating that the high acidity induces the degradation of the surfactant template, whereby the hydrolysis of the alkoxy bridges is catalyzed by hydrochloric acid, as illustrated in Scheme 1.

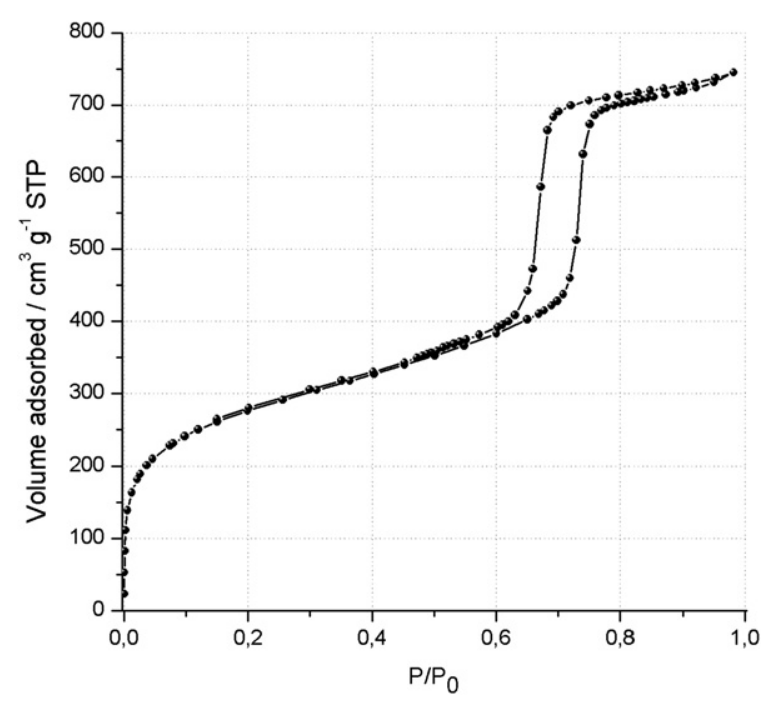

Fig. 6 Nitrogen isotherms of the ethenylene-bridged PMO synthesized at the optimum $\mathrm{pH}$ in the presence of $n$-butanol (E-EBP-12). The singlestep desorption isotherm indicates cylindrical mesopores which are open at both ends.

$$
\left.-\mathrm{O}-\left(\mathrm{CH}_{2}\right)_{n}-\mathrm{O}-\left(\mathrm{CH}_{2}\right)_{\mathrm{n}}-\stackrel{\mathrm{H}_{3} \mathrm{O}^{+}}{\longrightarrow} \text { 2- } \mathrm{-O}-\left(\mathrm{CH}_{2}\right)_{n}-\mathrm{OH}\right]
$$

Scheme 1 Acid catalyzed hydrolysis of the ethylene-oxide chains in the surfactant template

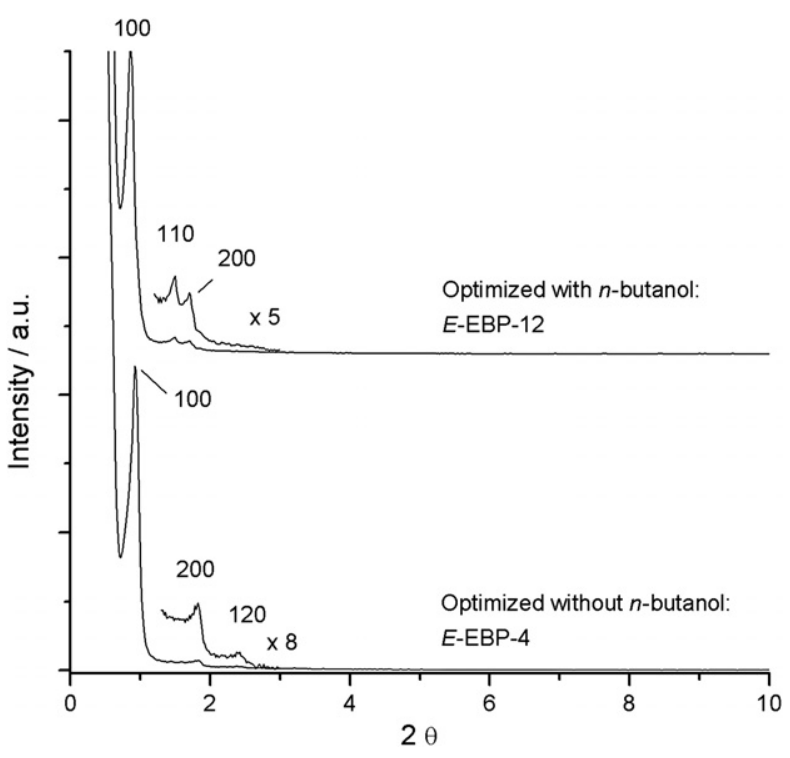

Fig. 7 XRD-plots of ethenylene-bridged PMOs synthesized at the optimized $\mathrm{pH}$, without $n$-butanol (E-EBP-4) and with $n$-butanol (E-EBP-12).

In Fig. 7, low-angle XRD-patterns are given of the ethenylenebridged PMOs synthesized at the optimized $\mathrm{pH}$, without $n$-butanol (E-EBP-4) and with $n$-butanol ( $E$-EBP-12) as a cosolvent. The XRD pattern of $E$-EBP-4 reveals an intense peak at $2 \theta \approx 0.92^{\circ}$, which is attributed to the (100) diffraction peak from the $2 \mathrm{D}$ hexagonal unit cells $\left(\mathrm{a}_{0} \approx 11.1 \mathrm{~nm}\right)$. Two smaller, but well-resolved peaks which can be assigned to the (200) and (120) reflections are also apparent, indicating a well-ordered structure. The XRD pattern of $E$-EBP-12 reveals (100), (110) and (200) diffraction peaks also suggesting a well-ordered 2D hexagonal structure. In comparison to $E$-EBP-4, $E$-EBP-12 has a larger unit cell $\left(\mathrm{a}_{0} \approx 11.9 \mathrm{~nm}\right)$, which explains the difference in both diffraction patterns.

These XRD-results indicate that well-ordered ethenylenebridged PMOs can be synthesized both with and without $n$-butanol, by optimizing the $\mathrm{pH}$ of the synthesis mixture.

Fig. 8 gives a typical TEM image of a diastereoisomeric pure ethenylene-bridged PMO (E-EBP-15). An inset of the Fourier

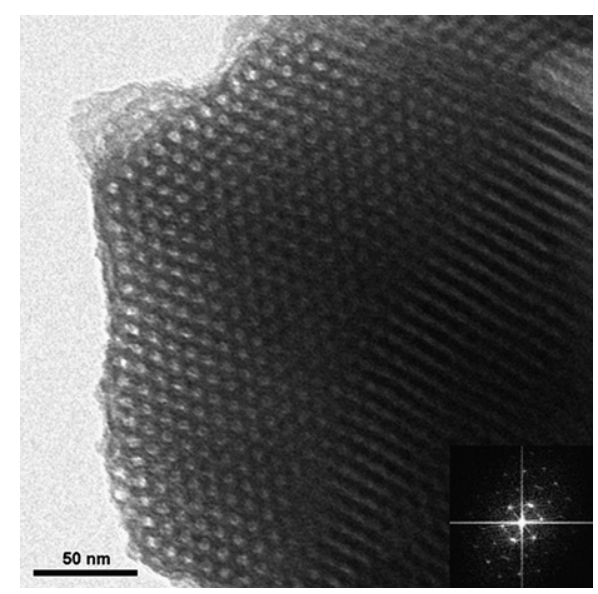

Fig. 8 TEM-image of ethenylene-bridged PMO (E-EBP-15) with the Fourier transform in the inset. 
transform of the structure is also included. The PMO particles are very well ordered, exposing a $P 6 \mathrm{~mm}$ symmetry.

The concentration of $n$-butanol also has an influence on the material properties, as illustrated by the data in Table 2 .

At a $\mathrm{pH}$ of 0.3 , a $n$-butanol:P123 ratio of 155 gives the best material in terms of surface area and pore volume. The $n$-butanol concentration also influences the microporosity of the PMOs. When the $n$-butanol:P123 ratio is raised to 195 , a substantial fraction $(63.4 \%)$ of the total pore volume is micropore volume. This suggests that the ethylene oxide chains of P123 are less likely to withdraw from the solution into the micelle core that consists primarily of hydrophobic propylene oxide chains. This is also supported by the fact that at high $n$-butanol:P123 ratios the pore diameter increases, indicating that the micelle cores swell.

\section{The role of cosolvent in controlling the morphology of ethenylene-bridged PMOs}

The manner in which organic-inorganic species self-assemble into mesostructured architectures determines the particle morphology. Many factors such as micelle structure, hydrolysis and condensation rates of the silica precursors and the interactions between surfactant micelles and condensating silicate species effect the final morphology of the particles. As illustrated by the SEM images in Fig. 9, for ethenylene-bridged PMOs, the presence of cosolvents and the variation of cosolvent concentration has a tremendous effect on the particle morphology.

For the PMOs synthesized in the presence of $n$-ethanol (E-EBP-20) and $n$-propanol (E-EBP-21), hexagonal crystal-like discs are predominant (Fig. 9A and 9B respectively). The discs of $E$-EBP-20 have a diameter of approximately $1.6 \mu \mathrm{m}$ and are about $0.2 \mu \mathrm{m}$ thick, while the hexagonal shaped discs of $E$-EBP21 are about $0.8 \mu \mathrm{m}$ in diameter and $0.2 \mu \mathrm{m}$ thick. The angles between adjacent edges of the discs are $120^{\circ}$. When taking a closer look at the mesostructure of these crystal-like discs with TEM, the channels are perpendicular to the disc plane (Fig. 10B). These findings suggest that $n$-ethanol and $n$-propanol facilitate the assembly of surfactant-organosilica composite micellar rods into hexagonal crystal nuclei via the cooperative self-assembly mechanism. As previously reported for MCM-41 with similar morphologies,$^{30}$ such hexagonal crystal-like structures can arise when all faces of the nucleus grow at the same rate (Fig. 10C). When this is not the case distorted hexagonal discs or discs with irregular shapes are obtained.

By applying $n$-butanol as a cosolvent (E-EBP-15), the morphology completely shifts from crystal-like hexagonal discs to rope-like macrostructures with lengths of over $150 \mu \mathrm{m}$ and diameters ranging from 2 to $10 \mu \mathrm{m}$ (Fig. 9D). Moreover, the difference in morphology between $E$-EBP-15 and the other

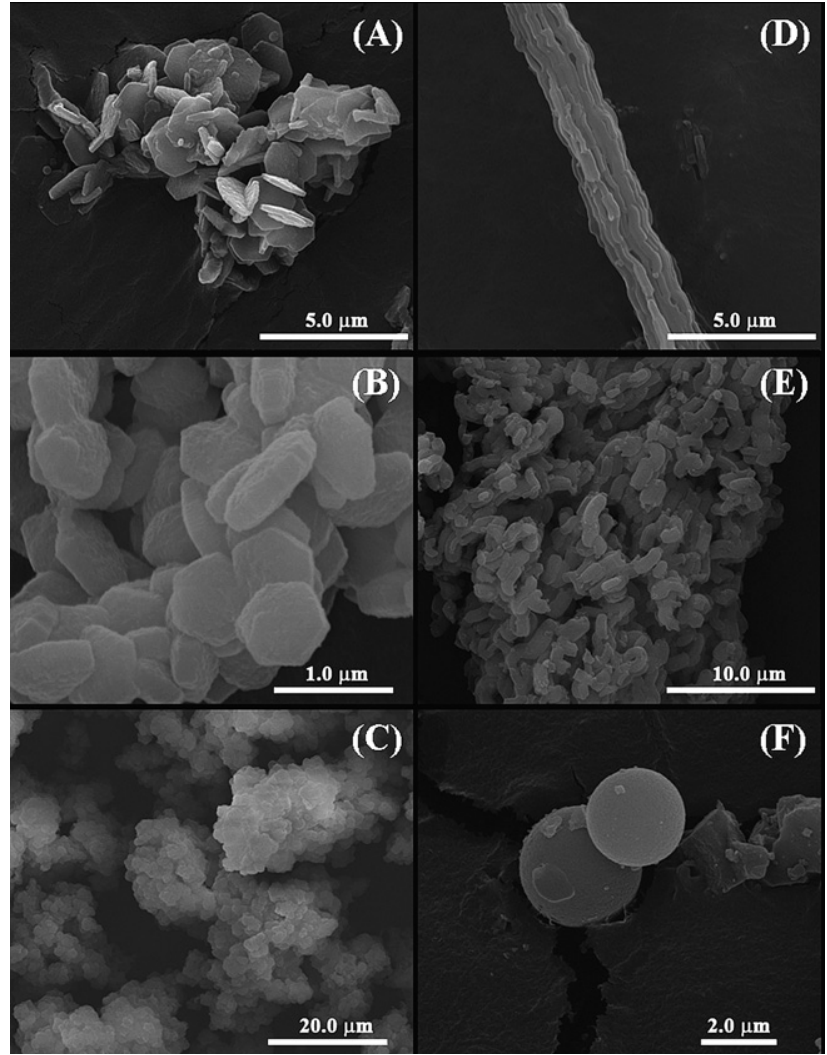

Fig. 9 FE-SEM micrographs of ethenylene-bridged PMOs prepared in the presence of various cosolvent and cosolvent concentrations: (A) $n$-ethanol, (B) $n$-propanol, (C) $n$-pentanol, (D) $n$-butanol:P123 = 95: 1 , (E) $n$-butanol:P123 = $115: 1$ and (F) $n$-butanol:P123 = 175: 1 .

samples, is visible to the eye. While other PMOs discussed in this paper are fine powders, $E$-EBP-15 is fibrous. The alteration in morphology caused by changing the cosolvent suggests that the cosolvent effects the micelle curvature and growth of the micellar aggregates. If the cosolvent is located at the surfactantorganosilica interface, it influences the interactions between these species and effects the particle growth and morphology. In the presence of $n$-butanol, the surfactant-organosilica composite micellar rods seems to grow faster along the fibre-axis than along the axis perpendicular to the pore channels, as sketched in Fig. 11.

By increasing the butanol:P123 molar ratio from 95 ( $E$-EBP$15)$ to 115 (E-EBP-16), the morphology changes from isolated fibres to clusters of short curved rods, ranging from 2 to $3.5 \mu \mathrm{m}$ in length and about $0.9 \mu \mathrm{m}$ in width (Fig. 9E). By further increasing the $n$-butanol:P123 ratio to 175 (E-EBP-18) the morphology

Table 2 Influence of the $n$-butanol concentration on the PMO properties

\begin{tabular}{lllllll}
\hline PMO samples & Butanol:P123 & $\mathrm{S}_{\mathrm{BET}} / \mathrm{m}^{2} \mathrm{~g}^{-1}$ & $\mathrm{~V}_{\mathrm{t}} / \mathrm{cm}^{3} \mathrm{~g}^{-1}$ & $\mathrm{~V}_{\text {mes }} / \mathrm{cm}^{3} \mathrm{~g}^{-1}$ & $\mathrm{~V}_{\text {mic }} / \mathrm{cm}^{3} \mathrm{~g}^{-1}$ & $\mathrm{~V}_{\text {mic }} / \mathrm{V}_{\mathrm{t}} \%$ \\
\hline E-EBP-15 & 95 & 767 & 0.77 & 0.65 & 0.12 & 12 \\
E-EBP-16 & 115 & 652 & 0.66 & 0.57 & 0.09 & 15.6 \\
E-EBP-17 & 135 & 695 & 0.70 & 0.60 & 0.10 & 13.6 \\
E-EBP-11 & 155 & 908 & 0.95 & 0.80 & 0.15 & 6.2 \\
E-EBP-18 & 175 & 854 & 0.74 & 0.56 & 0.18 & 15.8 \\
E-EBP-19 & 195 & 766 & 0.41 & 0.15 & 0.26 & 6.2 \\
\hline
\end{tabular}



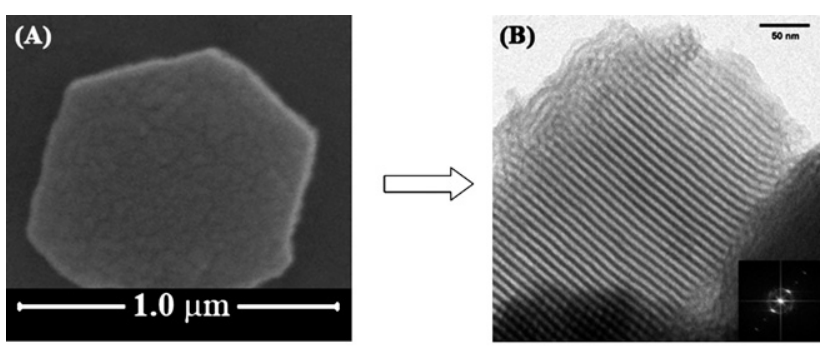

(C)

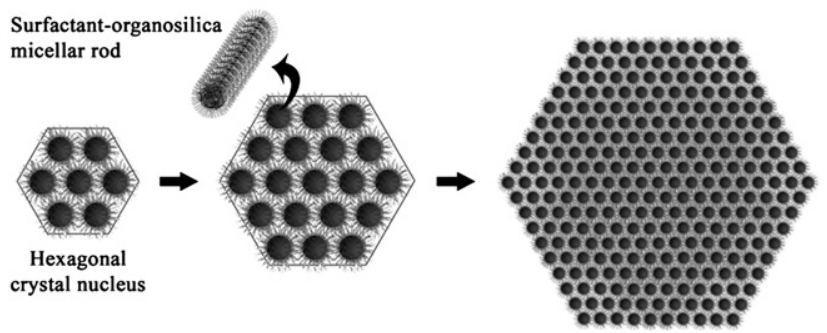

Fig. 10 (A) FE-SEM (disc viewed from top) and (B) TEM image (disc viewed edge on) of a hexagonal disc with $P 6 \mathrm{~mm}$ pore ordering ( $E$-EBP21). (C) Crystal growth of ethenylene-bridged PMOs with crystal-like disc morphologies.

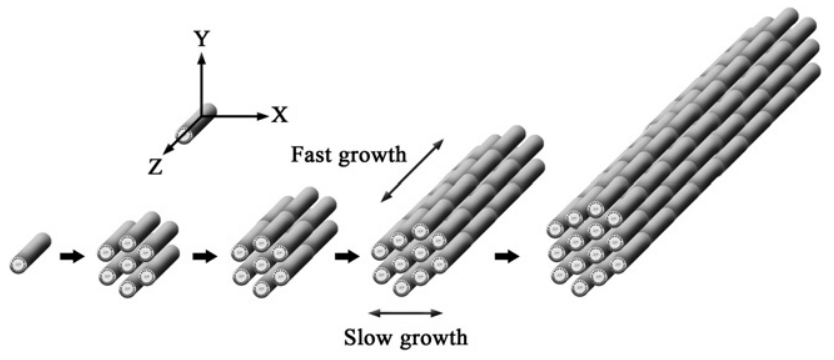

Fig. 11 Schematic illustration of ethenylene-bridged PMO growth in the presence of $n$-butanol at low concentrations. The surfactant-organosilica composite micellar rods grow faster along the $\mathrm{Z}$-axis than along the $\mathrm{X}$ - and $\mathrm{Y}$-axes.

changes to primarily spherical particles of approximately 1.9 to $3.8 \mu \mathrm{m}$ (Fig. 9F). The concentration of $n$-butanol is found to effect the dispersion of the organosilica particles, with the formation of spheres at high alcohol concentrations similar to the modified Stöber method. ${ }^{31}$ Due to the high acidity of the reaction mixture in which $E$-EBP-18 is formed, most of the spheres are aggregated and are accompanied by irregular shapes. When $n$-pentanol is used as a cosolvent (E-EBP-22), large clusters of irregular shapes are formed (Fig. 9C). The nonuniform morphology is probably caused by the low miscibility of $n$-pentanol in water.

Influence of the aging temperature on the properties of ethenylene-bridged PMOs

In Table 3 the pore and surface properties, as a function of the aging temperature, of some ethenylene-bridged PMOs, are given. An increase in aging temperature from $50{ }^{\circ} \mathrm{C}$ to $90{ }^{\circ} \mathrm{C}$, results in a pore enlargement of about $69 \%$. It is commonly known that the hydrophilicity of the EO blocks in poly(alkylene oxide) triblock copolymers, $(\mathrm{EO})_{x}(\mathrm{PO})_{x}(\mathrm{EO})_{x}$, such as pluronic $\mathrm{P} 123$, is temperature dependent. By raising the aging temperature of the reaction mixture, the hydrophobicity of the EO blocks increases, upon which they withdraw into the hydrophobic micelle cores. This results in a swelling of the micelle cores, causing the pores to enlarge. However, no additional increase in pore size is observed when the aging temperature is further elevated from $90{ }^{\circ} \mathrm{C}$ to $150{ }^{\circ} \mathrm{C}$. This indicates that some of the EO blocks, instead of withdrawing into the micelle cores, decompose. Furthermore, it is feasible that the PMO mesostructure does not permit further swelling of the micelles in the pores as it is only flexible to a certain extent.

Coinciding with an increase in pore size or elevated aging temperature, the micropore volume decreases. When raising the temperature from $70{ }^{\circ} \mathrm{C}$ to $150{ }^{\circ} \mathrm{C}$, the micropore volume decreases about $81 \%$. This could be attributed to the collapse or sealing of the micropores in the PMO pore walls upon withdrawal of the EO blocks. However, with increasing aging temperature the total pore volume does not decrease. On the contrary, an increase in total pore volume is apparent, which can be related to an increase in mesopore volume. These findings suggest that with increasing temperature, at least some of the EO-blocks of the surfactant template gather together instead of withdrawing in the micelle core. Doing so, the micropore connections which would normally be generated in the pore walls between adjacent mesopores upon template removal, are transformed into secondary mesopores. This hypothesis may also explain why the mesopores do not enlarge when the aging temperature is raised beyond $90{ }^{\circ} \mathrm{C}$. These results confirm similar findings made by Galarneau et $a l^{32}$ and Jaroniec and coworkers. ${ }^{33}$ The low micropore volume of E-EBP-23, synthesized at $50{ }^{\circ} \mathrm{C}$, can also be explained by the temperature dependent behavior of Pluronic P123. At relatively low temperatures, the repulsion between hydrated PEO chains drives the micelles to such a distance that adjacent micelles do not share their

Table 3 Influence of aging temperature on the PMO properties

\begin{tabular}{lllllll}
\hline PMO samples & $\mathrm{T}_{\text {aging }} /{ }^{\circ} \mathrm{C}$ & $\mathrm{S}_{\mathrm{BET}} / \mathrm{m}^{2} \mathrm{~g}^{-1}$ & $\mathrm{~V}_{\mathrm{t}} / \mathrm{cm}^{3} \mathrm{~g}^{-1}$ & $\mathrm{~V}_{\text {mes }} / \mathrm{cm}^{3} \mathrm{~g}^{-1}$ & $\mathrm{~V}_{\text {mid }} / \mathrm{cm}^{3} \mathrm{~g}^{-1}$ & $\mathrm{~V}_{\text {mid }} / \mathrm{V}_{\mathrm{t}} \%$ \\
\hline$E$-EBP-23 & 50 & 535 & 0.54 & 0.53 & 0.01 & 1.9 \\
$E$-EBP-24 & 50 & 736 & 0.69 & 0.60 & 0.09 & 1.9 \\
$E$-EBP-25 & 70 & 996 & 1.00 & 0.82 & 0.18 & 18.0 \\
$E$-EBP-12 & 90 & 1014 & 1.15 & 0.99 & 0.16 & 13.0 \\
$E$-EBP-26 & 110 & 971 & 1.18 & 1.00 & 0.13 & 11.5 \\
$E$-EBP-27 & 150 & 783 & 1.14 & 0.04 & 8.1 & 3.4
\end{tabular}

${ }^{a}$ Same molar composition as E-EBP-12, see Table 1. 
hydration shells. ${ }^{32}$ As a consequence, the PEO chains do not fully penetrate the mesopore walls, resulting in a low micropore volume.

\section{Conclusions}

Ethenylene-bridged PMOs with high surface areas and pore volumes combined with good structural ordering were attained by fine-tuning the reaction mixture acidity. By varying the cosolvent (n-ethanol, $n$-propanol, $n$-butanol and $n$-pentanol) and tuning its concentration, PMOs with crystal-like disc shaped, fibrous and spherical particle morphologies were synthesized. The synthesis temperature is found to influence the pore size, structure, connectivity and volume of ethenylene-bridged PMOs.

\section{Acknowledgements}

$\mathrm{CV}, \mathrm{FV}$ and PVDV are indebted to the FWO-Vlaanderen (Fund for Scientific Research Flanders) and the University of Ghent (BOF) for a research grant and financial support. HF and KPdJ acknowledge support from the National Research School Combination Catalysis (NRSCC).

\section{References}

1 A. Stein, B. J. Melde and R. C. Schroden, Adv. Mater., 2000, 12, 1403.

2 F. Hoffmann, M. Cornelius, J. Morell and M. Froba, Angew. Chem., Int. Ed., 2006, 45, 3216.

3 P. Van der Voort, C. Vercaemst, D. Schaubroeck and F. Verpoort, Phys. Chem. Chem. Phys., 2008, 10, 347.

4 T. Asefa, M. J. MacLachan, N. Coombs and G. A. Ozin, Nature, 1999, 402, 867.

5 S. Inagaki, S. Guan, Y. Fukushima, T. Ohsuna and O. Terasaki, J. Am. Chem. Soc., 1999, 121, 9611.

6 C. Vercaemst, M. Ide, B. Allaert, N. Ledoux, F. Verpoort and P. Van der Voort, Chem. Commun., 2007, 2261.

7 M. A. Wahab, S. Sudhakar, E. Yeo and A. Sellinger, Chem. Mater., 2008, 20, 1855

8 T. Asefa, M. J. MacLachlan, H. Grondey, N. Coombs and G. A. Ozin, Angew. Chem., Int. Ed., 2000, 39, 1808.

9 X. Y. Bao, X. Li and X. S. Zhao, J. Phys. Chem. B, 2006, 110, 2656.
10 A. Sayari, S. Hamoudi, Y. Yang, I. L. Moudrakovski and J. R. Ripmeester, Chem. Mater., 2000, 12, 3857.

11 A. Sayari and Y. Yang, Chem. Commun., 2002, 2582.

12 L. Zhang, Q. H. Yang, W. H. Zhang, Y. Li, J. Yang, D. M. Jiang, G. R. Zhu and C. Li, J. Mater. Chem., 2005, 15, 2562.

13 W. H. Wang, S. H. Xie, W. Z. Zhou and A. Sayari, Chem. Mater., 2004, 16, 1756.

14 Y. D. Xia, Z. X. Yang and R. Mokaya, Chem. Mater., 2006, 18, 1141.

15 C. Vercaemst, H. Friedrich, P. E. de Jongh, A. V. Neimark, B. Goderis, F. Verpoort and P. Van Der Voort, J. Phys. Chem. C, 2009, 113, 5556.

16 C. Vercaemst, P. E. de Jongh, J. D. Meeldijk, B. Goderis, F. Verpoort and P. Van Der Voort, Chem. Commun., 2009, 4052.

17 S. Inagaki, S. Guan, T. Ohsuna and O. Terasaki, Nature, 2002, 416, 304.

18 M. Kuroki, T. Asefa, W. Whitnal, M. Kruk, C. Yoshina-Ishii, M. Jaroniec and G. A. Ozin, J. Am. Chem. Soc., 2002, 124, 13886.

19 M. P. Kapoor, S. Inagaki, S. Ikeda, K. Kakiuchi, M. Suda and T. Shimada, J. Am. Chem. Soc., 2005, 127, 8174.

20 J. Liu, Q. H. Yang, M. P. Kapoor, N. Setoyama, S. Inagaki, J. Yang and L. Zhang, J. Phys. Chem. B, 2005, 109, 12250.

21 Q. H. Yang, J. Liu, J. Yang, M. P. Kapoor, S. Inagaki and C. Li, J. Catal., 2004, 228, 265.

22 S. Shylesh and A. P. Singh, Microporous Mesoporous Mater., 2006, 94, 127.

23 D. M. Jiang, Q. H. Yang, H. Wang, G. R. Zhu, J. Yang and C. Li, J. Catal., 2006, 239, 65.

24 M. Jaroniec, Nature, 2006, 442, 638.

25 L. X. Zhang, W. H. Zhang, J. L. Shi, Z. Hua, Y. S. Li and J. Yan, Chem. Commun., 2003, 210.

26 K. Landskron, B. D. Hatton, D. D. Perovic and G. A. Ozin, Science, $2003,302,266$.

27 B. Johnson-White, M. Zeinali, K. M. Shaffer, C. H. Patterson, P. T. Charles and M. A. Markowitz, Biosens. Bioelectron., 2007, 22, 1154.

28 V. Rebbin, R. Schmidt and M. Froba, Angew. Chem., Int. Ed., 2006, 45, 5210 .

29 J. R. Kremer, D. N. Mastronarde and J. R. McIntosh, J. Struct. Biol., 1996, 116, 71

30 Y. R. Ma, L. M. Qi, J. M. Ma, Y. Q. Wu, O. Liu and H. M. Cheng, Colloids Surf., A, 2003, 229, 1.

31 M. Grun, A. A. Kurganov, S. Schacht, F. Schuth and K. K. Unger, J. Chromatogr., A, 1996, 740, 1.

32 A. Galarneau, N. Cambon, F. Di Renzo, R. Ryoo, M. Choi and F. Fajula, New J. Chem., 2003, 27, 73.

33 M. Kruk, M. Jaroniec, C. H. Ko and R. Ryoo, Chem. Mater., 2000, 12, 1961. 